\title{
Electrocorticographic Dynamics as a Novel Biomarker in Five Models of Epileptogenesis
}

\author{
Dan Z. Milikovsky, ${ }^{1}$ Itai Weissberg, ${ }^{1}$ Lyn Kamintsky, ${ }^{1,2}$ Kristina Lippmann, ${ }^{3}$ Oosnat Schefenbauer, ${ }^{1}$ Federica Frigerio, ${ }^{4}$ \\ [Dassimo Rizzi, ${ }^{4}$ Liron Sheintuch, ${ }^{1}$ CDaniel Zelig, ${ }^{1}$ - Jonathan Ofer, ${ }^{1}$ Annamaria Vezzani, ${ }^{4}$ \\ and Alon Friedman ${ }^{1,2}$ \\ ${ }^{1}$ Departments of Physiology and Cell Biology, Cognitive and Brain Sciences, Zlotowski Center for Neuroscience, Ben-Gurion University of the Negev, \\ Beer-Sheva 84105, Israel, ${ }^{2}$ Department of Medical Neuroscience, Dalhousie University, Halifax, Nova Scotia B3H 4R2, Canada, ${ }^{3}$ Institute of \\ Neurophysiology, Charité-University of Medicine Berlin, 10117 Berlin, Germany, and ${ }^{4}$ Department of Neuroscience, Experimental Neurology, \\ IRCCS-Istituto di Ricerche Farmacologiche "Mario Negri”, 20156 Milan, Italy
}

Postinjury epilepsy (PIE) is a devastating sequela of various brain insults. While recent studies offer novel insights into the mechanisms underlying epileptogenesis and discover potential preventive treatments, the lack of PIE biomarkers hinders the clinical implementation of such treatments. Here we explored the biomarker potential of different electrographic features in five models of PIE. Electrocorticographic or intrahippocampal recordings of epileptogenesis (from the insult to the first spontaneous seizure) from two laboratories were analyzed in three mouse and two rat PIE models. Time, frequency, and fractal and nonlinear properties of the signals were examined, in addition to the daily rate of epileptiform spikes, the relative power of five frequency bands (theta, alpha, beta, low gamma, and high gamma) and the dynamics of these features over time. During the latent pre-seizure period, epileptiform spikes were more frequent in epileptic compared with nonepileptic rodents; however, this feature showed limited predictive power due to high inter-and intra-animal variability. While nondynamic rhythmic representation failed to predict epilepsy, the dynamics of the theta band were found to predict PIE with a sensitivity and specificity of $>\mathbf{9 0 \%}$. Moreover, theta dynamics were found to be inversely correlated with the latency period (and thus predict the onset of seizures) and with the power change of the high-gamma rhythm. In addition, changes in theta band power during epileptogenesis were associated with altered locomotor activity and distorted circadian rhythm. These results suggest that changes in theta band during the epileptogenic period may serve as a diagnostic biomarker for epileptogenesis, able to predict the future onset of spontaneous seizures.

Key words: biomarker; EEG; epilepsy; epileptogenesis; stroke; traumatic brain injury

Significance Statement

Postinjury epilepsy is an unpreventable and devastating disorder that develops following brain injuries, such as traumatic brain injury and stroke, and is often associated with neuropsychiatric comorbidities. As PIE affects as many as $20 \%$ of brain-injured patients, reliable biomarkers are imperative before any preclinical therapeutics can find clinical translation. We demonstrate the capacity to predict the epileptic outcome in five different models of PIE, highlighting theta rhythm dynamics as a promising biomarker for epilepsy. Our findings prompt the exploration of theta dynamics (using repeated electroencephalographic recordings) as an epilepsy biomarker in brain injury patients.

\section{Introduction}

Postinjury epilepsy (PIE) is a devastating consequence of common brain insults, including traumatic brain injury (TBI) and

\footnotetext{
Received Aug. 1, 2016; revised Feb. 16, 2017; accepted Feb. 24, 2017

Author contributions: D.Z.M. and A.F. designed research; D.Z.M., I.W., and D.Z. performed research;D.Z.M., L.K. K.L., O.S., F.F., M.R., L.S., J.O., and A.V. contributed unpublished reagents/analytic tools; D.Z.M. analyzed data; D.Z.M., I.W., L.K., and A.F. wrote the paper.

This study was supported by the European Union Seventh Framework Programme (FP7/2007-2013; Grant agreement 602102, EPITARGET; to A.F.), the Israel Science Foundation (to A.F.), the Binational Israel-USA Foundation (to
}

stroke. It is often resistant to antiepileptic drugs and is associated with further neuropsychiatric comorbidities. Recent advancements in the understanding of PIE pathogenesis (i.e., epileptogenesis) have given rise to the hope that preventive strategies may soon be ready for clinical translation, with several studies having

\footnotetext{
A.F.), The German Research Foundation (to A.F.), the CURE Epilepsy Foundation, the Nova Scotia Health Research Foundation, and the Canada Foundation for Innovation.

The authors declare no competing financial interests.

Correspondence should be addressed to Alon Friedman, Department of Medical Neuroscience, Dalhousie
} University, Halifax, NS B3H 4R2, Canada. E-mail: alon.friedman@dal.ca. 
already demonstrated the ability to prevent experimental PIE by targeting injury-induced vascular pathology (more specifically dysfunction of the blood-brain barrier) and subsequent neuroinflammatory signaling (Zeng et al., 2009; van Vliet et al., 2012; Bar-Klein et al., 2014; Weissberg et al., 2015). However, as $<20 \%$ of injured patients will develop epilepsy within a 2 year follow-up period (Pitkänen and Immonen, 2014), the large number of TBI patients required to demonstrate the statistical efficacy of these preventive treatments in the absence of biomarker-based inclusion criteria has hindered the clinical phase transition (with trials estimated to cost $>\$ 40,000,000$; White et al., 2010). Moreover, all-inclusive trials are also probable to result in a higher number of patients experiencing side effects (without having needed the treatment) than patients who would benefit from PIE prevention (Friedman et al., 2014). Not only would a reliable biomarker allow adequately powered and reasonably priced trials focusing on a relevant patient population (Pitkänen et al., 2016), it would also allow sensitive identification of patients prone to future seizures as candidates for preventive treatments.

Early attempts at identifying relevant epilepsy biomarkers trace back to the middle of the previous century (Roseman and Woodhall, 1946; Cant, 1976), focusing mainly on electrographic features of neuronal hyperexcitability. While additional approaches, including genetic or anatomical screening, and blood oxygenation monitoring were explored for PIE prediction (Pitkänen et al., 2016), electrographic signals not only seem to have the greatest clinical accessibility but also the most promising potential to reflect aberrant network functionality and connectivity. Recent studies have suggested the diagnostic potential of electrographic features such as epileptiform spikes (White et al., 2010) or high-frequency oscillations (HFOs; Engel and da Silva, 2012), yet these approaches have so far failed to find clinical implementation, presumably due to limited predictive specificity (Pitkänen et al., 2016).

Having previously examined the capacity of 22 different electrographic features (reflecting time, frequency, and fractal and nonlinear signal properties) to represent ictal changes for robust detection of epileptic seizures, we demonstrated the pathological relevance of brain rhythm fluctuations (Bar-Klein et al., 2014; Levy et al., 2015; Weissberg et al., 2015; Rizzi et al., 2016). Further encouraged by findings correlating the theta rhythm in particular with epilepsy-related cognitive decline (Chauvière et al., 2009), here we set out to question the predictive potential of the previously examined 22 electrographic features and additional features of rhythm dynamics during the preseizure epileptogenic period in three models of PIE. In these three vascular injury models (Levy et al., 2015; Weissberg et al., 2011, 2015; Fig. 1), our analysis revealed that changes in theta $(3-8 \mathrm{~Hz})$ activity over time show great potential for epilepsy prediction. These results were further successfully validated in a rat stroke model (Lippmann et al., 2016) and in a rat electrically induced status epilepticus (EISE) model (Noè et al., 2013).

\section{Materials and Methods}

Animals. Experiments of the mice model and the rat stroke model were conducted following approval from the ethics committee of Ben-Gurion

K. Lippmann's present address: Carl-Ludwig-Institute for Physiology, Leipzig University, 04103 Leipzig, Germany.

L. Sheintuch's present address: The Department of Neurobiology, Weizmann Institute of Science, Rehovot 76100 , Israel.

DOI:10.1523/JNEUROSCI.2446-16.2017

Copyright $\odot 2017$ the authors $\quad 0270-6474 / 17 / 374451-12 \$ 15.00 / 0$
University of the Negev, Beer-Sheva, Israel. Some of the data derive from previous studies (Levy et al., 2015; Weissberg et al., 2015; Lippmann et al., 2016). EISE experiments were performed following approval from the ethics committee of Mario Negri Institute, Milan, Italy, as published (Noè et al., 2013), and the recordings were supplied by Noè and Vezzani.

Telemetric electrocorticography and intracerebroventricular pump implantation in mice. The procedures were performed as described previously (Levy et al., 2015; Weissberg et al., 2011, 2015). Briefly, 2- to 3-month-old mice (FVB/N mice, Harlan Biotech; and C57BL/6 mice, The Jackson Laboratory) were anesthetized with isoflurane $(0.8-2 \%)$. In a stereotaxic frame, two $0.7-\mathrm{mm}$-diameter holes were drilled through the skull (all coordinates herein are relative to bregma, $3 \mathrm{~mm}$ posterior and 2 $\mathrm{mm}$ lateral) for screws serving as electrodes. Screws were connected to a wireless transmitter (Data Science International) placed in a pocket formed in the subcutaneous region of the back of the animal. One 0.7$\mathrm{mm}$-diameter hole was drilled $(0.5 \mathrm{~mm}$ posterior, $1 \mathrm{~mm}$ lateral $)$ and served for solution perfusion by an osmotic pump (ALZET) placed in the same subcutaneous pocket. The pumps were removed $7 \mathrm{~d}$ following the procedure. Pumps for $\mathrm{FVB} / \mathrm{N}$ mice were filled with $0.4 \mathrm{~mm}$ bovine serum albumin (BSA; Sigma-Aldrich), $100 \mathrm{ng} / \mathrm{ml}$ transforming growth factor (TGF)- $\beta 1$ (PeproTech), or $0.4 \mathrm{~mm}$ BSA plus $300 \mu \mathrm{M}$ SJN2511 (a selective blocker of the TGF- $\beta$ type I receptor/ALK5; Tocris Bioscience), herein, blocker. Pumps for C57BL $/ 6$ mice were filled with $5 \mu \mathrm{g} / \mathrm{ml}$ interleukin- 6 (IL-6; PeproTech) or $0.4 \mathrm{~mm} \mathrm{BSA.} \mathrm{All} \mathrm{solutes} \mathrm{were} \mathrm{dissolved} \mathrm{in} \mathrm{artificial}$ CSF (ACSF) prepared as described previously (Seiffert et al., 2004). Sham control animals were implanted with pumps containing ACSF or $0.4 \mathrm{~mm}$ fluorescein isothiocyanate-conjugated $70 \mathrm{kDa}$ dextran (Sigma-Aldrich) in ACSF. After recovery, animals were placed in a behavior room maintained on a $12 \mathrm{~h}$ circadian cycle for $14 \mathrm{~d}$ with food and water accessible $a d$ libitum. A receiver placed under the cage of each animal collected (sampling rate, $1 \mathrm{KH}$ ) and transmitted the signals to a personal computer.

Locomotor activity measurement. Locomotor activity in freely moving mice was measured as described previously (Tarasiuk et al., 2014; Jukic et al., 2015) using the implanted wireless transmitter (Data Science International) as mentioned above. Briefly, the derivative of the signal strength received from the implanted transmitter is correlated with the locomotion of the animal. To assess circadian rhythmicity, the derivative was divided into epochs of 2 min with 1 min overlap, and the mean was calculated for each epoch. Then, a moving average with a constant of 500 was applied (Fig. 1A,B).

Telemetric deep recordings and photothrombosis-induced cortical ischemia. Procedures were performed as described previously (Lippmann et al., 2016). Briefly, for electrode implantation, rats (males; weight, 200$300 \mathrm{~g}$; Harlan Biotech) were anesthetized by ketamine-xylazine (1.6 and $0.6 \mathrm{mg} / \mathrm{kg}$ body weight, i.p., respectively) and maintained by isoflurane $(0.8 \%)$ via a mask in a stereotaxic frame. After drilling three holes in the skull, a Teflon-coated platinum iridium wire $33 \mu \mathrm{m}$ in diameter (Science Products) connected to the DSI transmitter wire was located $2.5 \mathrm{~mm}$ lateral, $3.5 \mathrm{~mm}$ caudal, and $2.2 \mathrm{~mm}$ ventral into the CA1 region of the right hippocampus (Swanson, 2004). The second electrode was fixed to a screw above the left cerebellum located $4.5 \mathrm{~mm}$ lateral and $5 \mathrm{~mm}$ dorsal to serve as an epidural reference. After a 4 d recovery period, a $48 \mathrm{~h}$ baseline recording was performed followed by the induction of stroke using Rose Bengal (Watson et al., 1985; Lapilover et al., 2012). Rose Bengal was administered $(20 \mathrm{mg} / \mathrm{kg}$, i.v. $)$ to the tail vein, and a halogen light beam (3.5 mm diameter) was directed on the exposed skull (1 mm posterior and $1 \mathrm{~mm}$ lateral to bregma) for $15 \mathrm{~min}$. The skin was sutured and treated with xylocain gel. Buprenorphine $(0.05 \mathrm{mg} / \mathrm{kg}$, s.c.) was administered. Recording continued for $9 \mathrm{~d}$ after photothrombosis (PT). A single animal was excluded due to multiple acute seizures occurring $<24 \mathrm{~h}$ after the procedure.

Telemetric deep recordings and EISE. For experimental details, see Noè et al. (2013). Briefly, male adult rats (weight, 300 g; Charles River Laboratories) were implanted under anesthesia with two bipolar depth electrodes inserted into the temporal poles of both hippocampi (posterior, $4.7 \mathrm{~mm}$; lateral, \pm 5 ; ventral, 5). For ground and reference electrodes, screws were placed in the nasal sinus and cerebellum, respectively. Following 7-10 d of recovery, $24 \mathrm{~h}$ of baseline recording was performed in freely moving rats. Then, rats were stimulated unilaterally in the CA3 


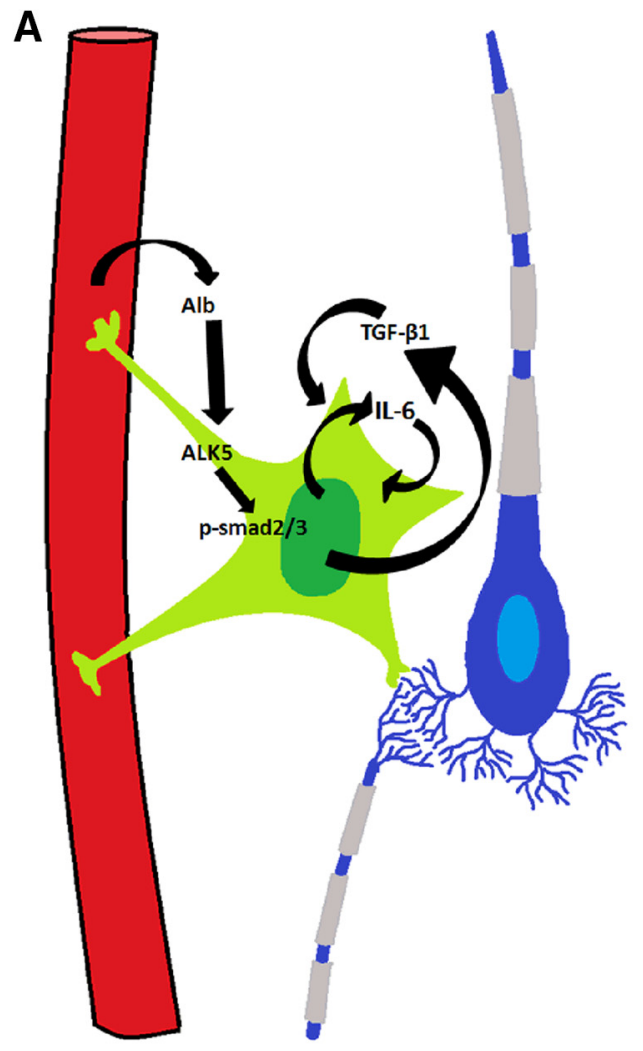

B

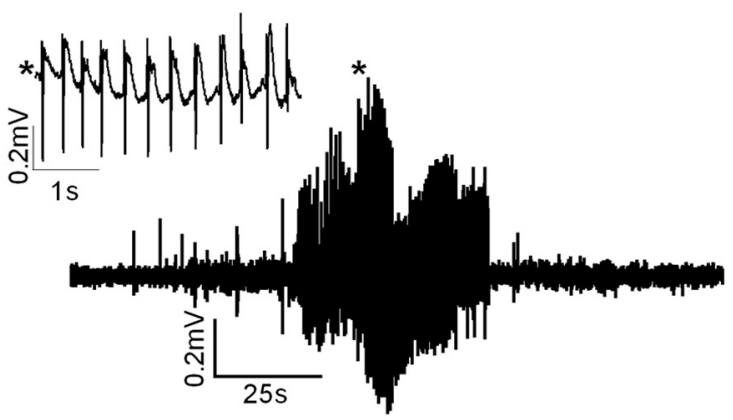

C

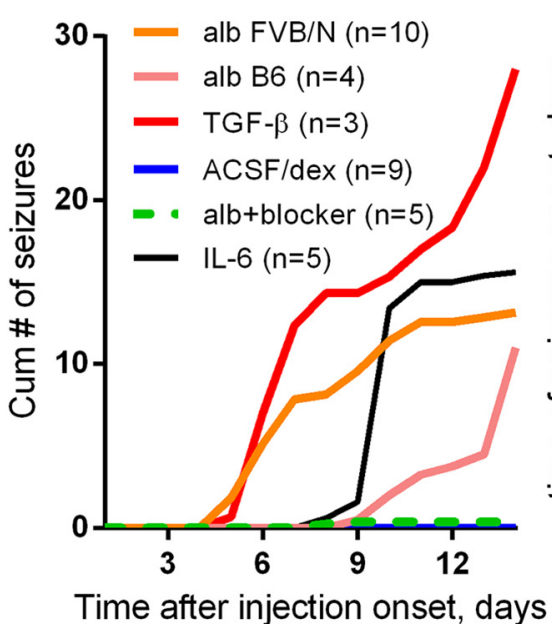

D

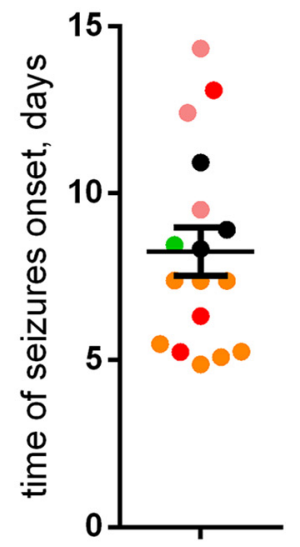

Time after injection onset, days

Figure 1. Mechanism-based models of PIE. $A$, The mechanisms mediating epileptogenesis in the studied PIE models include the following: serum albumin (Alb) extravasation (in regions with dysfunctional BBB) $\rightarrow$ activation of astrocytic TGF- $\beta$ receptors $\rightarrow$ alk5-mediated smad $2 / 3$ phosphorylation $\rightarrow$ transcriptional inflammatory changes promoting further TGF- $\beta 1$ and IL-6 secretion $\rightarrow$ reorganization of the neural network $\rightarrow$ spontaneous seizures. $B$, A representative spontaneous seizure, as recorded in a mouse treated intraventricularly with albumin. C, Plot of the accumulating number of seizures per day in the six treatment groups demonstrates a minimum duration of $4 \mathrm{~d}$ as the epileptogenic period. $\boldsymbol{D}$, Distribution of seizure onsets in the different models. dex, Dextran; B6, C57BL/6.

region of the ventral hippocampus for $90 \mathrm{~min}$ to induce status epilepticus (SE) as described previously $(50 \mathrm{~Hz} ; 400 \mu \mathrm{A}$ peak-to-peak; $1 \mathrm{~ms}$ biphasic square waves in 10 s trains delivered every 11 s; De Simoni et al., 2000; Noe et al., 2008). Following the induction, rats were recorded for 8-21 d at $400 \mathrm{~Hz}$. For the present study, recordings from 13 rats were analyzed, and 4 were excluded due to seizures detected before the fifth day after the SE (acute seizures).

Signal processing for seizure detection. For the unbiased detection of seizures and determination of epilepsy onset electrographic signals were analyzed using an in-house MatLab software as described previously (Bar-Klein et al., 2014) followed by a blind manual review. ECOG analysis was based on features extraction and artificial neuronal network (ANN). To train the detector, a $1.5 \mathrm{~h}$ ECOG segment composed of background activity, noise, artifacts, and 24 seizures lasting 10-60 s each recorded from three models of epilepsy: Pilocarpine, genetic (synapsin triple knockout), and albumin (Becker et al., 2008; Ketzef et al., 2011; Weissberg et al., 2011). Data were bandpass filtered $(2-100 \mathrm{~Hz})$ and buffered into $2 \mathrm{~s}$ epochs with $1 \mathrm{~s}$ overlap. References ANN vectors of both seizures and baseline activities were assigned with values of 1 and -1 , respectively. Twenty-two features previously used in brain signal analysis were extracted from each epoch. Then, a forward sequential selection algorithm (Whitney, 1971) was implemented to find the optimal features combination that will enable both minimal computational complexity and maximal quality of detection. The chosen subset includes energy, $12-20 \mathrm{~Hz}$ relative power $(\beta), 20-40 \mathrm{~Hz}$ relative power (low gamma), SD, curve length. These features were used to train an ANN (single hidden layer, $n=50$, back-propagation ANN; Rumelhat et al., 1986) with Powell-Beale conjugate gradient training (Powell, 1977). Following receiver operating characteristic (ROC) analysis, a threshold of 0.85 was set. A seizure was defined when at least five suprathreshold consecutive epochs were detected.

Signal processing for epileptogenesis detection. We examined the 22 features explored for seizure detection, among them the mean relative power in five frequency bands: theta $(3-8 \mathrm{~Hz})$; alpha $(8-12 \mathrm{~Hz})$; beta $(12-20 \mathrm{~Hz})$; low gamma $(20-40 \mathrm{~Hz})$; and high gamma $(30-100 \mathrm{~Hz}$; $30-70 \mathrm{~Hz}$ in the EISE model) for every $60 \mathrm{~s}$ of ECOG segment. We also tested the dynamic changes in these power bands during the epileptogenic period using linear regression, with the calculated slopes representing the extent of the change. Recordings were analyzed from the following: mice: intracerebroventricular albumin, $\mathrm{FVB} / \mathrm{N}(N=10)$; C57BL/6 $(N=4)$; intracerebroventricular TGF- $\beta(N=3)$; albumin with TGF- $\beta$ blocker $(N=7$; Weissberg et al., 2015); IL-6 $(N=5)$; and ACSF/dextran ( $N=9$; Levy et al., 2015; Weissberg et al., 2015); rats: PT rats $(N=13$; Lippmann et al., 2016); and EISE rats $(N=9$; Noè et al., 2013). One control animal was excluded as an outlier (due to noise resulting in a theta slope magnitude larger than the mean \pm 2.7 SDs of its group).

Signal processing for spike detection. ECOG recordings were bandpass filtered between 1 and $45 \mathrm{~Hz}$. Events higher than 2 times and lower than 10 times of the signal baseline were detected for each window of $1024 \mathrm{~ms}$. Detected events contained both epileptic spikes and other types of physiological/nonphysiological noise. To detect epileptic spikes, a wavelet transform (WT)-based method was implemented (Adeli et al., 2003). Automatic detection and clustering was followed by a blind human review. Detection was performed on days 2-4 after the surgery. Four animals from the Alb plus blocker group were excluded from all the presented analyses due to a highly variable and noisy signal that did not allow a reliable spike detection. 
Statistics. ROC analyses and $\mathrm{k}$-means clustering were performed using MatLab. Other statistical tests were performed using GraphPad Prism software. Relative power bands of ECOG and duration of epileptogenesis were compared by Mann-Whitney test. Survival analyses were performed using the Kaplan-Meier method with curves comparison using the Mantel-Cox test. In correlation tests Pearson's $r$ is presented. Fisher's exact test was implemented to compare the early-onset and late-onset seizures of the EISE model. All statistical tests are two tailed.

\section{Results}

Intracerebroventricular administration of albumin, TGF- $\beta$, or IL-6 as mechanism-based models of postinjury epilepsy

To identify a disease-relevant biomarker, we set out to explore electrographic features in mechanism-driven models of PIE. In addition to discovering the epileptogenic role of albumin, which is shown to activate TGF- $\beta$ signaling and a neuroinflammatory response (Cacheaux et al., 2009) with predominant IL-6 upregulation (Fig. 1A; Levy et al., 2015; Weissberg et al., 2011, 2015) and mimicking different stages of the pathogenic process following injury-induced blood-brain barrier (BBB) dysfunction, we show that intracerebroventricular infusion of albumin, TGF- $\beta$, or IL-6 results in seizures in $71 \%, 100 \%$, and $60 \%$ of the animals, respectively. Notably, while a few animals presented isolated seizures within $2 \mathrm{~d}$ after treatment, in most of the animals, spontaneous seizures developed after a latent period of $>4 \mathrm{~d}$. No seizures were detected in control (sham-implanted) animals $(N=9)$, and in six of seven mice cotreated with albumin and a TGF- $\beta$ blocker (Fig. $1 B-D)$. Interestingly, when considering all animals in the albumin-treated group, mice of the FVB/N strain showed significantly shorter epileptogenic periods compared with the C57BL/6 strain $[4.94 \pm 0.53 \mathrm{~d}(N=12)$ vs $12.08 \pm 1.4 \mathrm{~d}(N=3)$, respectively; $p=0.004$ ]. Seizures detected before $4 \mathrm{~d}$ following the insult were regarded as "acute seizures". An animal was considered epileptic if recurrent seizures were detected $4 \mathrm{~d}$ after perfusion onset or later. Seizures were documented over $30 \mathrm{~d}$ after perfusion onset. During most of the seizures, animals showed staring behavior and only rarely presented with generalized tonic-clonic manifestation (Weissberg et al., 2011, 2015). Bilateral cortical recordings performed in a few animals confirmed that seizures first occurred in the right (implanted) hemisphere and propagated to the contralateral cortex (data not shown).

\section{Daily rate of epileptiform spikes shows limited potential as a PIE predictive biomarker}

The latent period greatly varies between models of PIE (Pitkänen and Immonen, 2014), and it is not known when network modification of epileptogenesis starts. Evidence shows molecular and electrophysiological changes as early as $72 \mathrm{~h}$ after the injury (El-Hassar et al., 2007; Yaari et al., 2007; Levy et al., 2015; Weissberg et al., 2015). Thus, taking a clinically relevant approach that strives to detect a pathogenesis in its earliest stage, we focused our analysis on the electrographic changes during days $2-4$ after treatment onset.

As the epileptogenic period is often characterized by epileptiform spikes (White et al., 2010), we set out to test the predictive potential of a feature representing the daily rate of such spikes. ECOG spikes were detected automatically using WT, and the mean number of spikes per day (during days $2-4$; i.e., the preseizure period) was calculated for each animal (Fig. 2D). Generally, epileptic animals had significantly higher spike rates (123.3 \pm 45.46 vs $274.3 \pm 46.04$ spikes/d; $p=0.026$ ); however, rate values fluctuated greatly and lacked consistency throughout the epileptogenic period. ROC analyses of the predictive accuracy of spike rates at day 2, 3, and 4 revealed the following values: day 2: area under the curve $(\mathrm{AUC})=0.55, p=0.71$, and $95 \%$ confidence interval $(\mathrm{CI})=0.03-0.79$; day 3 : $\mathrm{AUC}=0.74, p=0.013$, and $\mathrm{CI}=0.58-0.91$; day $4: \mathrm{AUC}=0.71, p=0.034$, and $\mathrm{CI}=$ 0.53-0.89 (Fig. 2E).

\section{Features of rhythm-specific activity show meager potential as PIE biomarkers}

In addition to reports of theta band changes in SE models of epilepsy (Arabadzisz et al., 2005; Chauvière et al., 2009; Marcelin et al., 2009), we next calculated the relative power of ECOG activity in the delta, theta, alpha, beta, and low- and high-gamma rhythms (during the preseizure period of days 2-4). Overall, we found high variability within the groups with no significant differences between epileptic $(N=17)$ and nonepileptic $(N=19)$ animals. An exemplary depiction of rhythm-specific activity at day 4 (light time) demonstrates the overlap in values between the epileptic and nonepileptic animals (delta, $p=0.68$; theta, $p=$ 0.82 ; alpha, $p=0.71$; beta, $p=0.35$; low-gamma, $p=0.27$; high-gamma, $p=0.42$; Fig. $2 F$ ).

\section{Theta dynamics as a biomarker for epilepsy}

Despite the inability of frequency-band features to reliably reflect pathology, we hypothesized that changes in rhythmic activity over time may offer additional insight into disease development (expecting consistent activity in nonepileptic animals and rhythmic shifts associated with the epileptic transformation of the neuronal network). Among the examined bands, theta dynamics were found to offer the greatest promise, with small variability in nonepileptic animals and prominent changes in epileptic mice (Fig. 3A). Linear regression analyses further revealed a "safety range" of nonepileptic theta slopes (ranging around zero), with epileptic animals clearly falling outside this range (Fig. 3 C). A ROC analysis was next used to evaluate the predictive potential of two measures of theta dynamics: the absolute slope value of each animal (sensitivity I) and its distance from the mean of control group (sensitivity II), revealing AUC $=0.9102$ with $\mathrm{CI}=0.81$ 1.01 and $\mathrm{AUC}=0.9969$ with $\mathrm{CI}=0.99-1.01$, respectively $(p<$ 0.0001 for both; Fig. 3B).

The optimal operational point (OOP) was then calculated for each ROC curve (as the curve point with maximal distance from randomized classification; Fig. 3B, dashed line). Comparison of Kaplan-Meier survival curves of animals divided based on the identified OOPs thresholds further confirmed significant differences between the epileptic and nonepileptic mice (Fig. 3D; $p<0.0001$ ).

As the false-negative results identified animals that had relatively late onsets, we also examined the correlation between the theta slopes and the duration of the epileptogenic period. Indeed, higher slope values were found to correlate with earlier onset of epilepsy (spontaneous seizures, $r=0.66, p=0.0036$; Fig. $3 E$ ). An inverse correlation was observed between the theta and highgamma slopes but not lower-frequency bands (delta, alpha, or beta). The coefficient correlation was greater among epileptic $(N=17, r=0.924, p<0.0001$; Fig. $3 F)$ compared with nonepileptic animals, regardless of treatment $(N=19, r=0.51, p=$ 0.021 ; Fig. $3 F$ ). These results further highlight the relevance of theta activity to the epileptogenic transformation of the neural networks. Interestingly, 23.5\% $(N=4)$ of epileptic animals showed a positive rather than a negative theta slope during days of early epileptogenesis. In these animals, this increase was followed by a decrease during the next few days of recordings, such that a few days before the first seizure, theta relative 

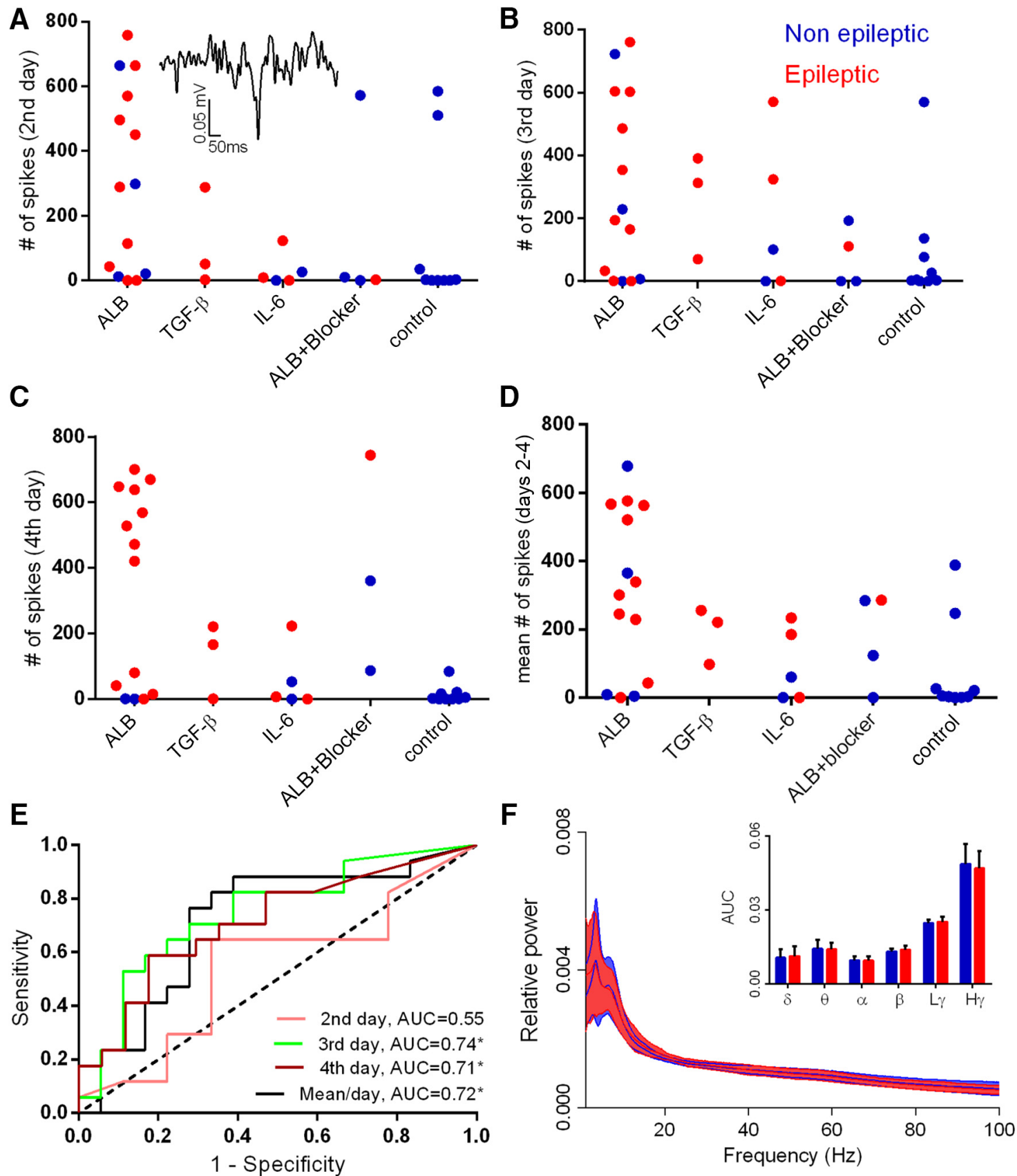

Figure 2. Spike rate and nondynamic representation of brain rhythms do not predict epilepsy. $\mathbf{A}-\boldsymbol{C}$, The daily rate of epileptiform spikes (see inset) for each animal calculated for days 2,3 , and 4 after treatment initiation in each treatment group. $\boldsymbol{D}$, Mean number of spikes per day for each animal. $\boldsymbol{E}$, ROC analysis reveals AUCs up to 0.74 for days 3 and 4 and the mean of days $2-4$, with only a 0.55 AUC for day 2 (not significantly different from randomized classification; AUC of 0.5 dotted black line). $\boldsymbol{F}$, Spectral analysis during the fourth day shows no significant differences in the tested frequency bands when comparing epileptic to nonepileptic animals. Solid lines represent the mean value, and background color depicts the SD. Dex, Dextran; $\mathrm{ALB}$, albumin; $\mathrm{L} \gamma$, low gamma; $\mathrm{H} \gamma$, high gamma.

power decreased (mean \pm SEM slope, $-0.0276 \pm 0.0079$; data not shown).

Since continuous EEG recordings during the latent period in human patients is difficult to implement, we next repeated the analysis using a "clinically relevant" approach by sampling 1-hlong ECOG segments (every $24 \mathrm{~h}$ starting from the first hour of the second day for 4 consecutive days). Analysis revealed an AUC of $0.66(p=0.1, \mathrm{CI}=0.46-0.86)$ and an AUC of $0.75(p=$ $0.0118, \mathrm{CI}=0.58-0.92$ ), respectively, for sensitivity I and II (Fig. $3 G$ ). When using 1-h-long segments every $12 \mathrm{~h}$ (seven segments), the AUCs were $0.78(p=0.004, \mathrm{CI}=0.63-0.94)$ and 0.873 $(p=0.0001, \mathrm{CI}=0.76-0.99)$, respectively, to sensitivity I and II (Fig. $3 \mathrm{H}$ ), supporting the translational potential of repeated theta power measure.

\section{Circadian rhythm is disturbed during epileptogenesis}

Changes in theta rhythm power are known to be associated with sleep/awake cycle and behavioral state in both rodents (Winson, 1974, 1978; O'Keefe and Recce, 1993) and human (Demenet and Kleitman, 1957; Kahana et al., 1999). We thus evaluated locomotor activity and compared the diurnal rhythmicity of theta changes with locomotor activity during epileptogenesis $(N=8)$ 
A

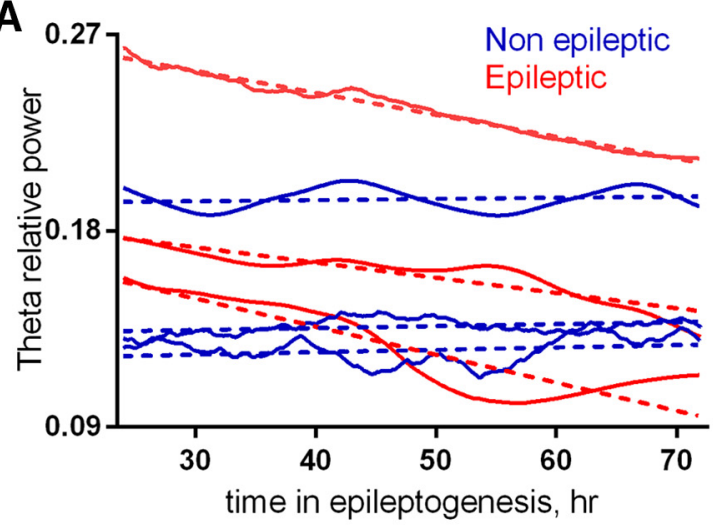

C

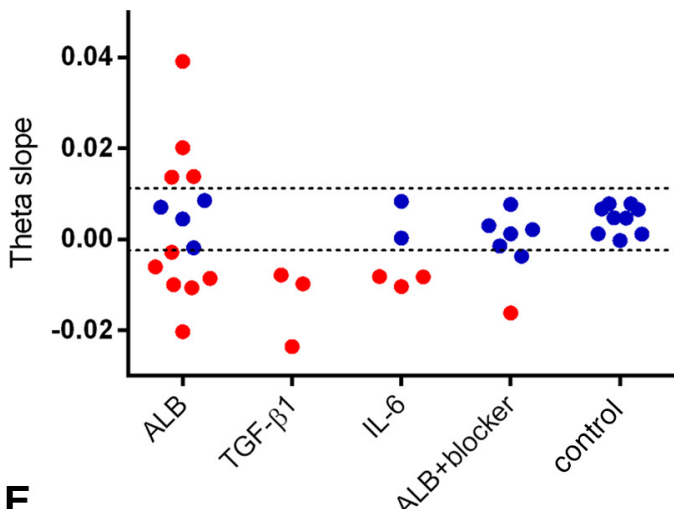

E

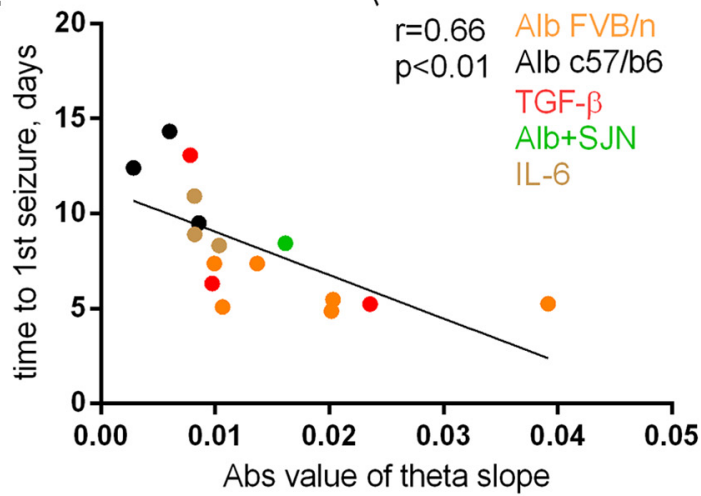

B

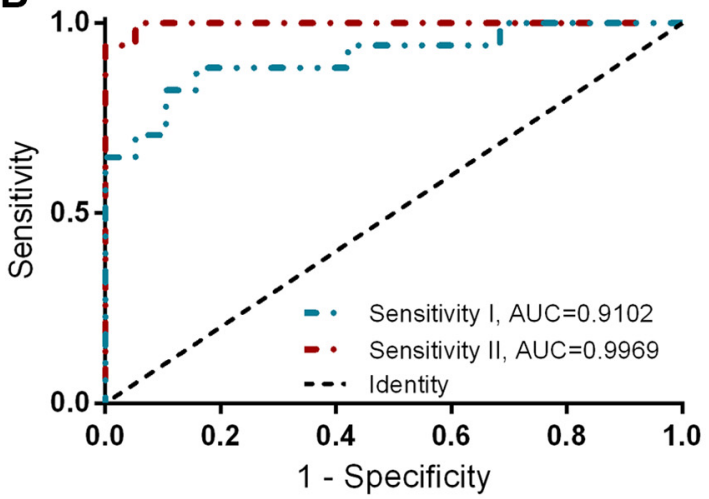

D

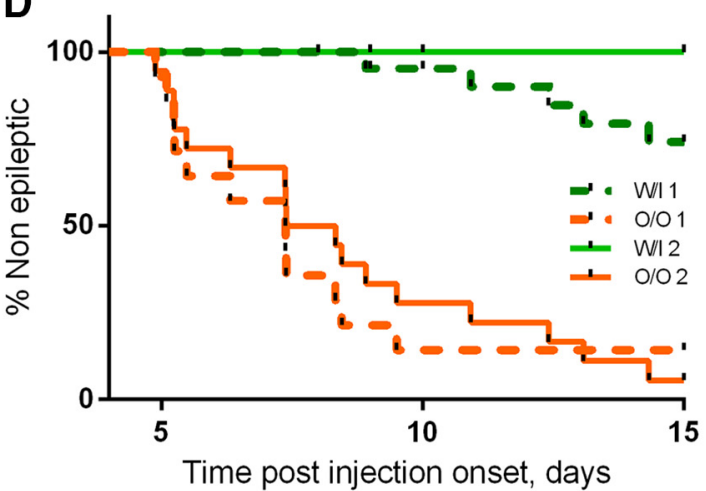

F

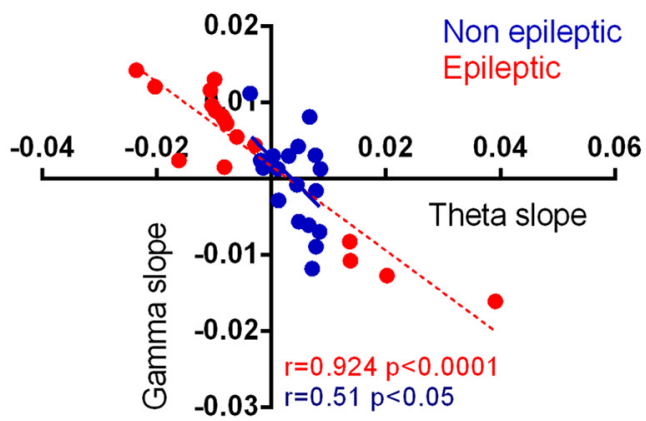

G

1 sample per day

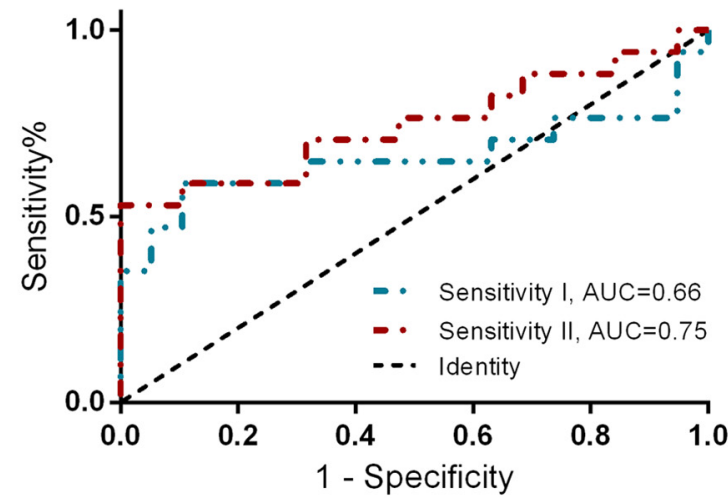

H

\section{2 samples per day}

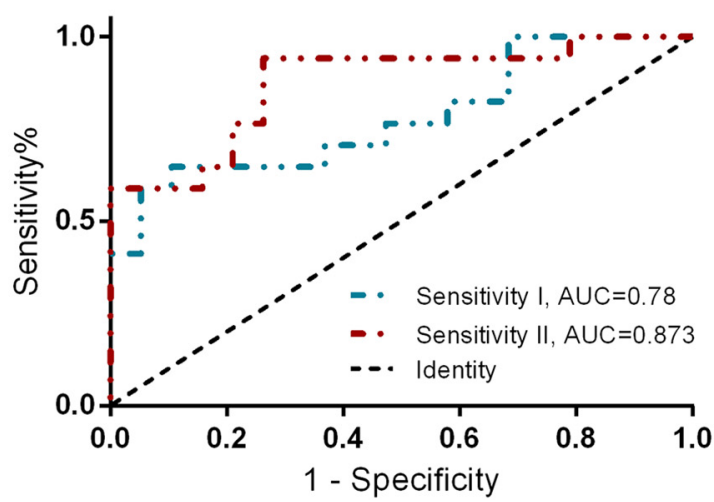

Figure 3. Theta dynamics as a biomarker for epilepsy. $\boldsymbol{A}$, Theta activity during the epileptogenic period from representative epileptic and nonepileptic animals ( $N=3$ in both groups). The smoothed raw traces and the corresponding linear fits are represented by continuous vs dashed lines, respectively. $\boldsymbol{B}$, ROC analysis was used to assess the predictive potential of two measures of theta dynamics: absolute value of the slope (sensitivity I: $A U C=0.9102, p<0.0001)$ and the distance of each slope from the mean slope of control group (sensitivity II: $A U C=0.9969, p<0.0001)$. The dotted black line indicates an AUC of 0.5 , a reference to randomized classification. C, Slopes of theta activity, superimposed on the margins of the safety range (dashed lines) calculated based on the 00P of sensitivity II. D, Kaplan-Meier analysis shows a significant difference between the 00P-classified groups ( $p<0.0001$, based on sensitivity I or II). (Figure legend continues.) 

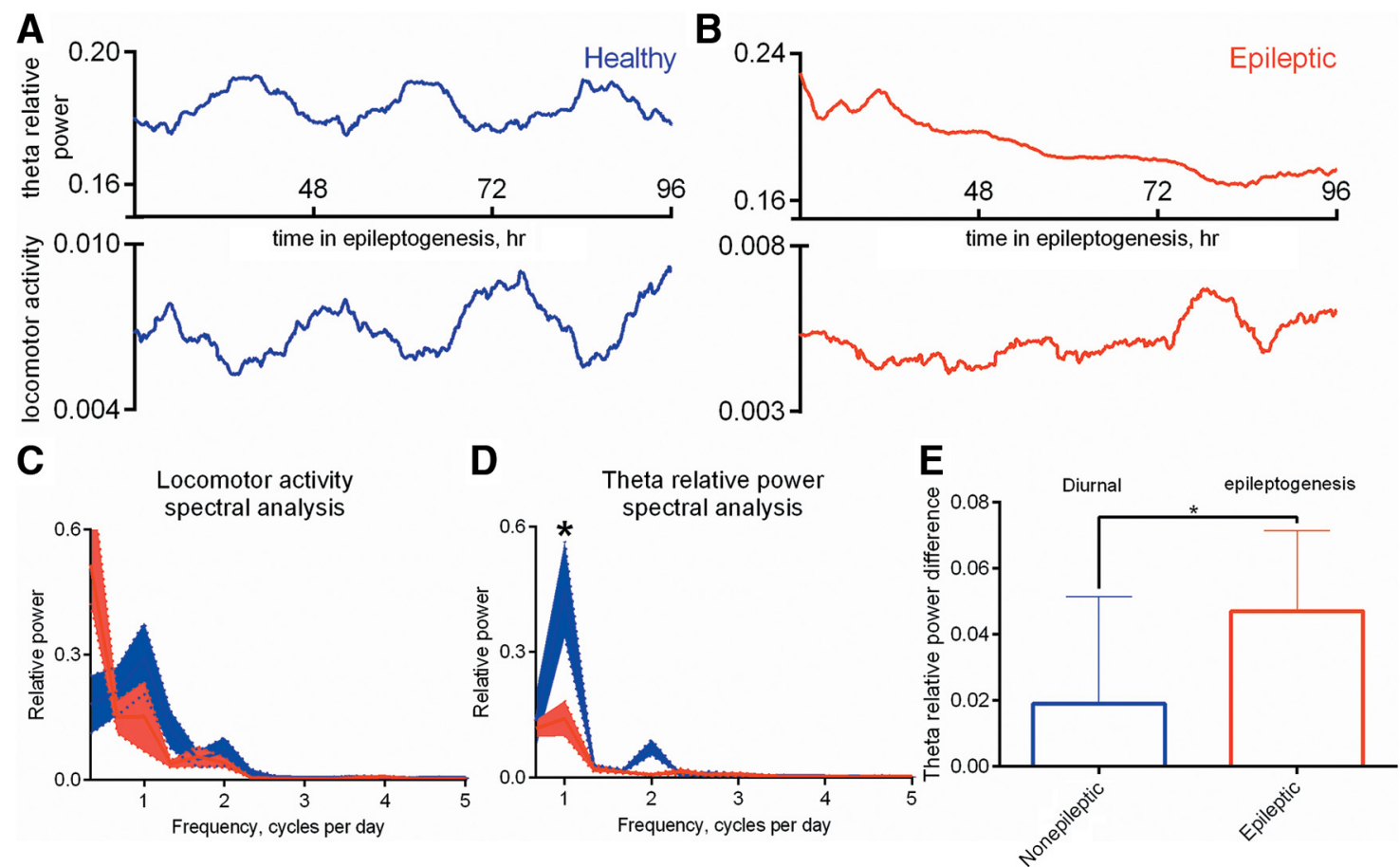

Figure 4. Circadian rhythm is disturbed during epileptogenesis. $A, B$, Representative examples of smoothed theta relative power and locomotor activity signals in nonepileptic mice $(\boldsymbol{A})$ or in mice undergoing epileptogenesis $(\boldsymbol{B})$. C, $\boldsymbol{D}$, Comparison of FFT analysis applied over the locomotor activity $(\boldsymbol{C})$ and theta relative power $(\boldsymbol{D})$ signals plotted in $\boldsymbol{A}$ and $\boldsymbol{B}$ between nonepileptic mice $(N=8)$ and mice undergoing epileptogenesis $(N=8)$. Comparison of the mean pick-to-pick theta relative power difference among nonepileptic animals $(N=8)$ and the difference between the start and end of epileptogenesis among animals undergoing epileptogenesis. $\boldsymbol{E}$, Presented are the median values plus the range. ${ }^{*} p=0.0378$.

and in nonepileptic animals $(N=8)$. Nonepileptic animals (Fig. $4 A$ ) demonstrated a significantly greater correlation between theta relative power and locomotor activity signal compared with animals undergoing epileptogenesis (Fig. 4B; median values, -0.41 vs -0.044 , respectively; $p=0.0003$; data not shown). This finding is consistent with the notion that slow rhythms are abundant during sleep with respect to wakefulness in preserved circadian rhythm (Rechtschaffen and Kales, 1968). Fast Fourier transform (FFT) analysis of locomotor activity revealed the dominant frequency of $1 \mathrm{cycle} / \mathrm{d}$ in nonepileptic mice, with no significant reduction in animals undergoing epileptogenesis $(p=0.19$; Fig. 4C). A similar analysis for frequency changes in theta rhythm revealed a significant reduction in the dominant frequency in animals undergoing epileptogenesis ( $p=0.0378$; Fig. $4 D)$, suggesting a greater sensitivity of the theta band to disruption of the circadian cycle. Notably, the mean day and night differences in theta power (days 2-4, pick to pick, as seen in Fig. 4A, top trace) among nonepileptic $(N=8)$ animals was smaller compared with the differences in theta power among animals undergoing epileptogenesis $(N=8$, start to end, as seen in Fig. $4 B$, top trace; $p=0.0378$; Fig. $4 E)$.

(Figure legend continued.) W/I, Within safety range; $0 / 0$, out of safety range. $\boldsymbol{E}$, Theta slopes are inversely correlated with the duration of the epileptogenic period $(N=17, r=0.66, p=$ 0.0036). $\boldsymbol{F}$, Theta and high-gamma slopes are inversely correlated in both epileptic $(N=17$, $r=0.924, p<0.0001)$ and nonepileptic $(N=19, r=0.51, p=0.021)$ animals. dex, Dextran. G, ROC analyses of a single sample per day (1-h-long segment): AUC $=0.66(p=0.1 \mathrm{Cl}=$ $0.46-0.86)$ and $\mathrm{AUC}=0.75(p=0.018, \mathrm{Cl}=0.58-0.92)$, respectively, to sensitivity l and II. $\boldsymbol{H}, \mathrm{ROC}$ analyses of two samples per day (1-h-long segment, every $12 \mathrm{~h}) \mathrm{AUC}=0.78$ ( $p=$ $0.004, \mathrm{Cl}=0.63-0.94)$ and $\mathrm{AUC}=0.873(p=0.0001, \mathrm{Cl}=0.76-0.99)$.
Theta dynamics as an epileptogenesis biomarker in additional PIE models

To test whether our findings in mice models of vascular PIE could be generalized to other PIE models, we next analyzed recordings from the PT model of poststroke epilepsy (Lippmann et al., 2016) and the EISE model (Noè et al., 2013).

As the PT rat model is associated with early-onset spontaneous seizures (Lippmann et al., 2016), theta dynamics were quantified for the first $24 \mathrm{~h}$ after PT, and only in rats without seizures during that period (Fig. $5 A, B$ ). No seizures were detected in the baseline period recorded before PT. Consistent with our findings in mice, nonepileptic animals showed little daily variability, whereas theta slopes of epileptic rats fluctuated significantly (Fig. $5 C$ ) and, similarly, were inversely correlated with high-gamma dynamics $(r=0.833, p=0.0004$; data not shown). The distance of the calculated slopes from the nonepileptic mean was used for ROC analysis and resulted in an AUC of $1(p=0.003, \mathrm{CI}=1-1$, Fig. 5D). Kaplan-Meier survival analysis revealed significantly different curves of animals within and out of the safety range derived from the OOP of the ROC analysis $(p=0.04$; data not shown).

In the EISE model (rats monitored with bilateral intrahippocampal electrodes at the Milan laboratory), theta slopes were calculated for the ipsilateral electrode for days 3-5 after SE induction. As this robust model induces seizures in all animals, theta slopes were used to classify animals into early versus late epilepsy onset (7-8 vs 11-18 d, respectively, classified based on the overall onset median at day 11). No seizures were detected in the baseline period recorded before the electrical stimulation. Unsupervised $\mathrm{k}$-means clustering divided the slopes into a group of six animals with zero-ranging slopes, consisting predominantly of late-onset animals (five of six; $p=0.046$, Fisher exact test; or $\mathrm{AUC}=0.85$, 


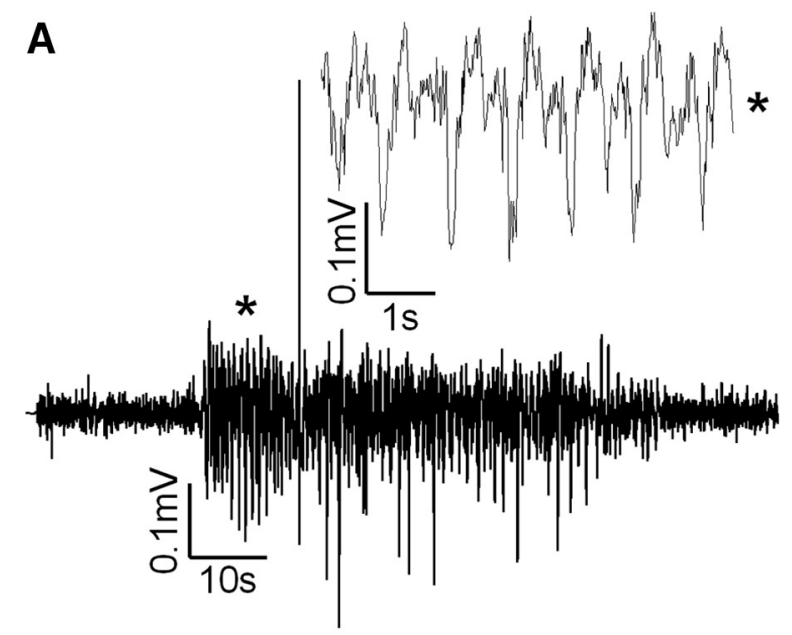

B
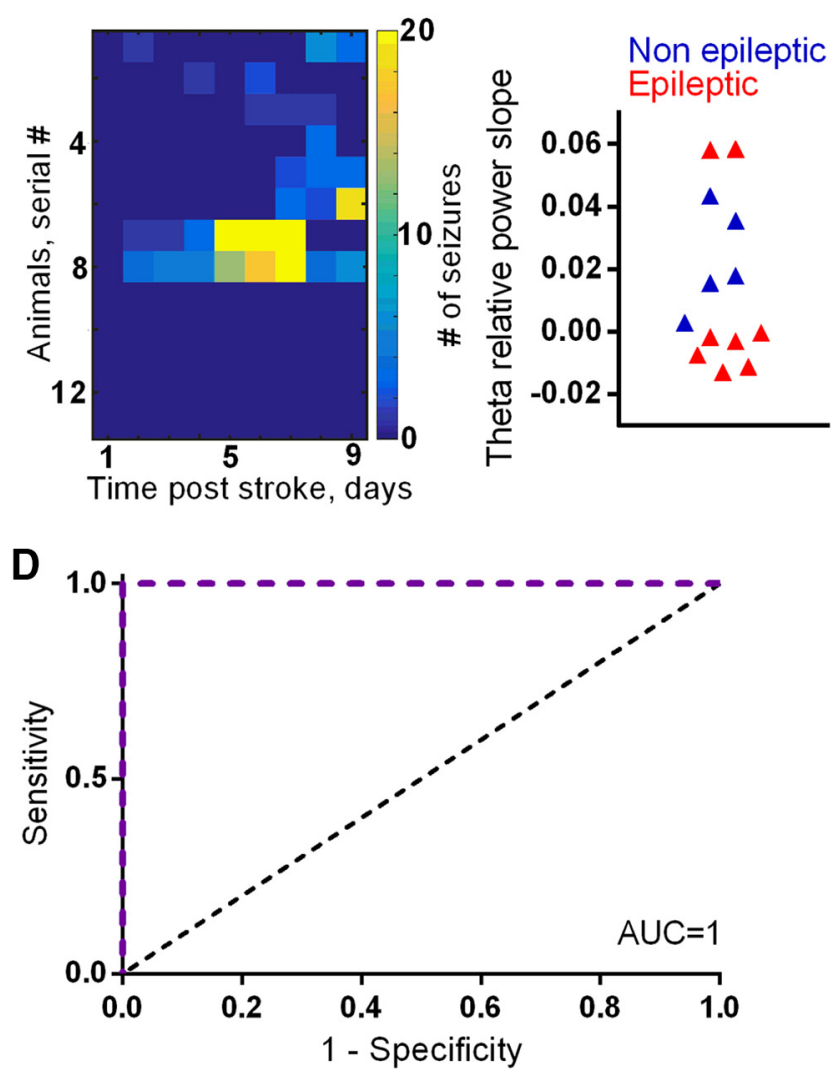

Figure 5. Theta dynamics as a biomarker for epilepsy in a stroke model of PIE. $A$, An example of a hippocampal seizure in a model of poststroke epilepsy. $\boldsymbol{B}$, A heat map of daily seizure rates shows that 5 of the 14 stroke animals remained nonepileptic throughout the recorded period. Among the epileptic animals, the seizure-free period ranged between 1 and $7 \mathrm{~d}$. C, D, Theta slopes (during the first $24 \mathrm{~h}$ from treatment initiation) of nonepileptic animals fall within a distinctive range $(\boldsymbol{C})$, the distance from which can accurately classify disease outcome, as evidenced in the ROC analysis $(\boldsymbol{D})$, revealing an AUC of $1(p=0.003)$. The dotted black line indicates an AUC of 0.5 , a reference to randomized classification.

$p=0.086, \mathrm{CI}=0.56-1.14 ;$ ROC analysis; data not shown); and a group of higher absolute slopes (two negative slopes and one positive slope; Fig. 6 A), representing early-onset rats. Linear correlation between seizure onset and absolute theta slope yielded a trend like that obtained in the mice models (Fig. $6 E ; r=0.653$ and $p=0.054$, data not shown) and revealed a negative theta-highgamma correlation $(p<0.0001$, data not shown). Interestingly, when comparing slopes between the two hippocampi, most rats showed similar theta fluctuations and seizure propagation from one hippocampus to the other (Fig. $6 C-E$, outlined square). In contrast, in a rat with stable theta values (outlined circle) seizures did not necessarily propagate to the contralateral hippocampus (Fig. 6E), supporting the hypothesis that theta changes are indicative of network modifications associated with a lower seizure threshold.

\section{Discussion}

We tested electrophysiological features in five rodent models of epilepsy (mice and rats) and found that theta activity dynamics show great promise as a diagnostic biomarker for epileptogenesis, a prognostic biomarker for PIE, and a pharmacodynamics biomarker to evaluate the efficacy of antiepileptic drugs. We further show that the degree of theta shift may also serve as a prognostic indicator for the duration of the epileptogenic period, with steeper slopes reflecting the earlier occurrence of seizures.

The potential of electrographic features to predict epilepsy has been explored in both patients and animals (Roseman and Woodhall, 1946; Cant, 1976; Gotman, 1991; White et al., 2010). Nonseizure epileptiform spikes were previously suggested to show predictive promise to seizures or epilepsy (Gotman, 1991; White et al., 2010). Our results confirm that spikes are more frequent during epileptogenesis; however, the high daily variability in spike rate (among both epileptic and nonepileptic animals) leads to a false-positive rate that limits the predictive specificity of this feature (Fig. 2). The detection of spikes in nonepileptic animals is consistent with previous studies (Bragin et al., 1995; White et al., 2010) and has been previously explained by noise or physiologic sources with a spike-like shape such as physiological dentate spikes (Bragin et al., 1995). Limited reliability of spike detectors may also underlie the inability of spikes to serve as a biomarker for epileptogenesis. In light of the limited frequency range of our recording systems, we were unable to assess the previously suggested diagnostic potential of HFOs $(80-600 \mathrm{~Hz}$; Engel and da Silva, 2012). However, while such oscillations were shown to benefit focus localization once epilepsy is confirmed (Engel and da Silva, 2012), their potential for the prediction of epilepsy was suggested to be limited (Pitkänen et al., 2016).

Interestingly, several studies have attracted our attention to the pathological relevance of theta activity, showing its decrease during epileptogenesis in the pilocarpine and kainic acid models (Arabadzisz et al., 2005; Chauvière et al., 2009; Marcelin et al., 2009) and implicating this decrease in cognitive failure (Chauvière et al., 2009). Importantly, our results point to a limited biomarker potential of theta activity when assessed at a single point in time, as a single measurement is susceptible to differences arising from electrode placement and variability between models. In contrast, we demonstrated predictive generalization when taking several measurements from each animal, quantifying the dynamic shift in theta activity rather than independent values. In most cases, a decrease in theta oscillations was found during the epileptogenic period, with greater decreases correlated with earlier onset of epilepsy (Figs. 3E, 6A,B).

The potential of theta dynamics as a general biomarker for epileptogenesis was shown by demonstrating a similar pattern in mice and rats as well as in intrahippocampal recordings following PT-induced stroke or EISE (Fig. 6A, B), with greater theta slopes associated with significantly shorter latent periods. Moreover, in the EISE model, the ipsilateral hemisphere that underwent epileptogenesis showed a high theta slope, whereas in the contralateral hemisphere the theta slope was near zero (Fig. 6C-E). This 
A

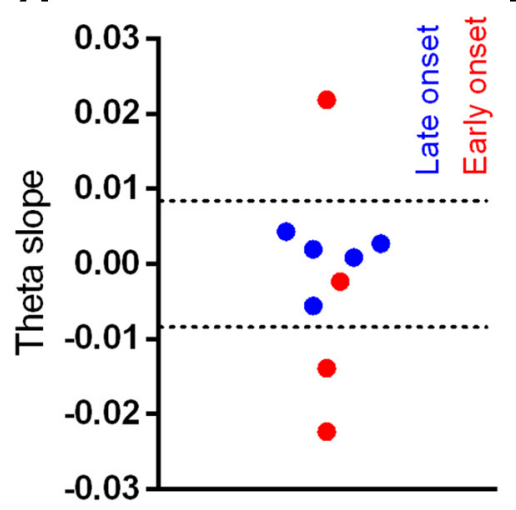

D
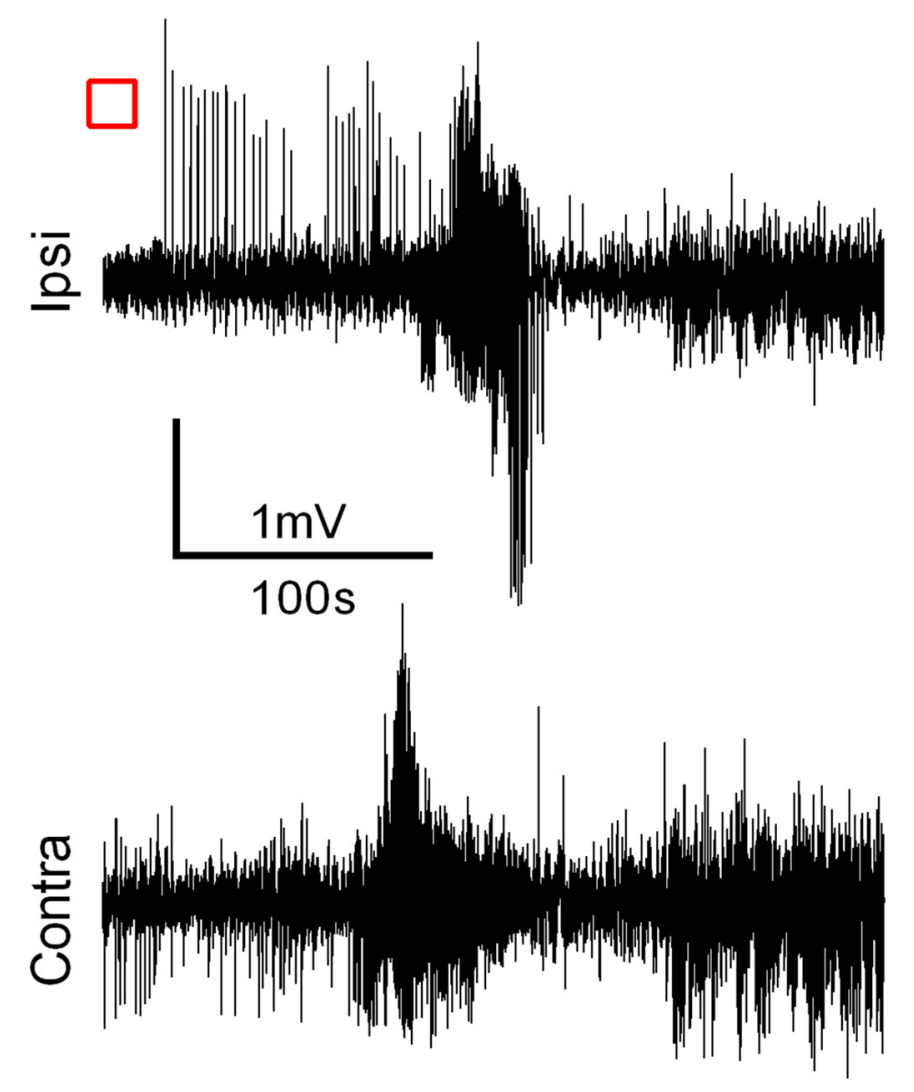

C

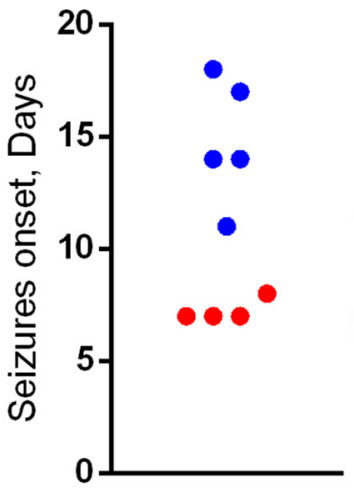

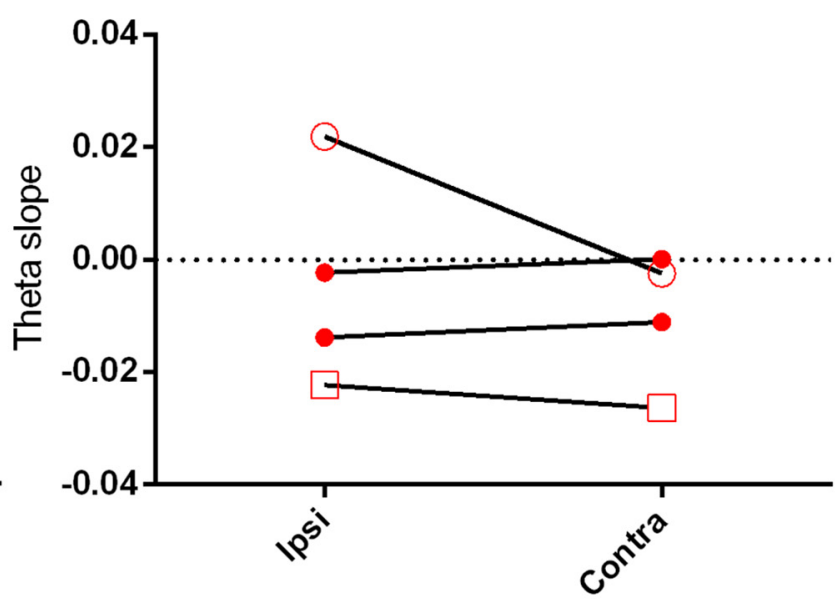

$E$
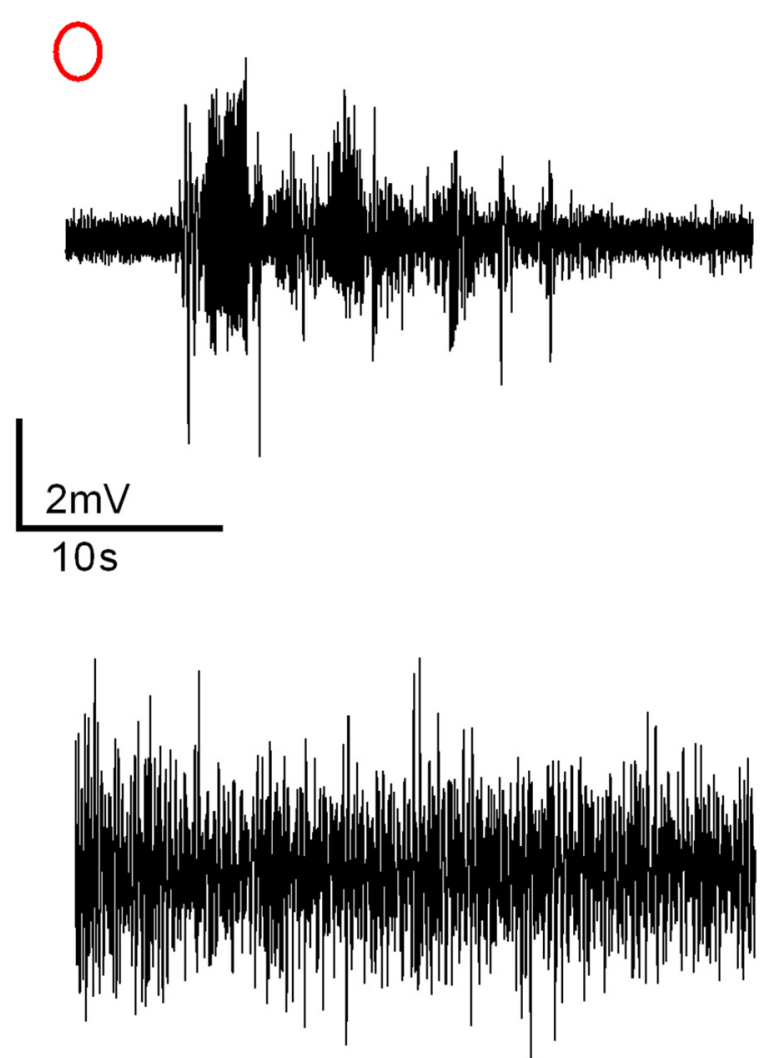

Figure 6. Theta dynamics as a biomarker for epilepsy in an EISE model of PIE. $\boldsymbol{A}, \boldsymbol{B}$, The k-means classification (dashed lines) of theta slopes (as recorded from the electrode ipsilateral to stimulation $(\boldsymbol{A})$ resulted in a division corresponding to the latency of the epileptogenic period $(\boldsymbol{B})$, with higher absolute slopes associated with earlier epilepsy onsets, whereas slow theta changes corresponded to slower disease development $(p=0.035)$. C, Comparison of ipsilateral and contralateral theta slopes in early-onset animals highlights one animal (outlined circle) with remarkably different values between the two hemispheres. $\boldsymbol{D}, \boldsymbol{E}$, Interestingly, this animal $(\boldsymbol{E})$ also had evident differences in intrahemispheric seizure propagation compared with an animal with relatively consistent slopes [ $\boldsymbol{D}$ (outlined square in $\boldsymbol{C}$ )].

finding strengthens the linkage between theta slope and epileptogenesis. Notably, the theta/PIE onset association was evident in four of the five models, excluding stroke-induced PIE. Such a lack of correlation may be due to the relatively short latent period in this model or because this model was the only one using ketamine anesthesia in addition to isoflurane. These reasons may underlie the necessity of comparing the theta slope of the average slope of nonepileptic animals in the PT model as opposed to the other models where the absolute value of the slope is informative as is. The discovered association between greater theta shifts and earlier PIE onsets is complemented by the previously suggested correlation between the loss of theta activity and memory deficits in experimental epileptic animals (Chauvière et al., 2009). In addition, a cognitive deficit itself was suggested as a predictive biomarker of PIE (Pascente et al., 2016). Interestingly, they both showed it in the pilocarpine-induced SE model of epilepsy. To- 
gether, these findings support the ability of theta rhythm to reflect clinically relevant network modifications that may not only underlie seizures but also contribute to cognitive decline, a hallmark of PIE and BBB dysfunction (Helmstaedter et al., 2003; Montagne et al., 2015). Future studies in models that do not result in $100 \%$ epilepsy are required to test whether changes in theta rhythm that are associated with cognitive decline can be distinguished from theta changes associated with epileptogenesis.

The onset of seizures in the PT model was relatively early (24-144 h after the stroke; Fig. 5B). In a previous study of the PT model, Kelly et al. (2001) reported seizures onset of 2 months after stroke. While early continues recordings were not performed by Kelly et al. (2001), and no long-term recordings were made in the data available for the present study, we cannot rule out that the detected seizures represent an acute response to the ischemic injury. However, the theta dynamics observed during the short postinjury period suggest that these represent a true reduction in seizure threshold within the local cortical network, regardless of how fast they develop.

The lack of theta changes in animals treated with intracerebroventricular albumin together with TGF- $\beta$ blockers (Fig. $3 C$ ) further suggests that theta dynamics may also serve as a pharmacodynamics biomarker, allowing the follow-up of preventive treatment efficacy. The observation that the sampling of $1 \mathrm{~h}$ recordings was sensitive in predicting epilepsy further indicates the translational potential of our findings.

Interestingly, four of the epileptic animals $(23.5 \%)$ in the minipump models showed an increase, rather than a decrease, in theta during days 2-4. As mentioned, the theta increase was followed by a decrease that preceded the first seizure. Previous reports showed that an increase in theta is a marker of sleep propensity under or following sleep deprivation (Aeschbach et al., 1997; Strijkstra et al., 2003; Vyazovskiy and Tobler, 2005). Our results are showing disturbed circadian rhythm during epileptogenesis (Fig. 3) that may explain the initial increase in theta.

Circadian distortions were previously described during the chronic period of epilepsy in both patients and rodents (Bastlund et al., 2005; Pung and Schmitz, 2006; Choi et al., 2016; Quigg et al., 2016). However, to our knowledge, this is the first report of disturbed circadian rhythms in animals undergoing epileptogenesis compared with nonepileptic animals. These results, while they should be confirmed in additional models and in human patients, call for the attention of clinicians and scientists to additional disturbances in brain activity among patients at risk for PIE.

While we show that theta changes predict PIE, we also found an increase in high-gamma activity $(30-100 \mathrm{~Hz})$ and a robust inverse correlation between the two bands. Under physiological conditions, gamma and theta oscillations are expected to behave in a phase- and amplitude-coupled manner (Buzsáki et al., 1983), and stimulation at theta frequencies was shown to induce gamma oscillations (Butler et al., 2016). Thus, our findings of strong negative theta-gamma correlation $(r=0.92$; Fig. $3 F)$ further highlight a transition from physiological to pathological network activity. An inverse correlation between theta and gamma relative power slopes was also observed in the nonepileptic group, but to a much lesser extent $(r=0.51$; Fig. $3 F)$. This may derive from the effects of surgical trauma or anesthesia rather than epileptogenesis. Importantly, increased gamma activity was previously associated with seizures (Köhling et al., 2000; Medvedev et al., 2000; Medvedev, 2002; Willoughby et al., 2003; Kobayashi et al., 2004, 2010; Herrmann and Demiralp, 2005; Traub et al., 2005; Wu et al., 2008; Inoue et al., 2008; Yamazaki et al., 2009; Andrade-
Valenca et al., 2012; Maheshwari et al., 2016) via the glutamatergic (Medvedev et al., 2000; Medvedev, 2002) NMDA pathway (Maheshwari et al., 2016). Thus, our evidence of increased gamma activity, together with the previously reported glutamatergic synaptogenesis in the albumin/TGF- $\beta$ PIE models (Weissberg et al., 2015) further implicate a process distorting physiological brain rhythms and connectivity, potentially through the modification of synaptic connections and reorganization of the neural network.

Our finding that C57BL/6 mice showed a slower theta decline and delayed seizure onsets compared with $\mathrm{FVB} / \mathrm{N}$ mice (Figs. $1 C, D, 3 E)$ is consistent with our previous report on low IL-6 response to TGF- $\beta$ in C57BL/6 mice (Levy et al., 2015) and their higher threshold for seizures and seizure-induced cell death (Borges et al., 2003; Yang et al., 2005; McLin and Steward, 2006; Bankstahl et al., 2012; Schauwecker, 2012). This relative straindependent resilience to an epileptogenic insult calls for future studies into the mechanisms underlying such a resilience.

In summary, we propose that theta rhythm alterations represent network modifications associated with a lower threshold for seizures and that this simple feature has a potential to become a reliable, noninvasive biomarker for epileptogenesis following brain insult. To actualize this potential, prospective clinical trials of repetitive EEG recordings in patients following brain insults are needed. We assert that these recordings have a high potential to reveal relative shifts in brain rhythms, serving as a biomarker for antiepileptogenic clinical studies.

\section{References}

Adeli H, Zhou Z, Dadmehr N (2003) Analysis of EEG records in an epileptic patient using wavelet transform. J Neurosci Methods 123:69-87. CrossRef Medline

Aeschbach D, Matthews JR, Postolache TT, Jackson MA, Giesen HA, Wehr TA (1997) Dynamics of the human EEG during prolonged wakefulness: evidence for frequency-specific circadian and homeostatic influences. Neurosci Lett 239:121-124. CrossRef Medline

Arabadzisz D, Antal K, Parpan F, Emri Z, Fritschy JM (2005) Epileptogenesis and chronic seizures in a mouse model of temporal lobe epilepsy are associated with distinct EEG patterns and selective neurochemical alterations in the contralateral hippocampus. Exp Neurol 194:76-90. CrossRef Medline

Bankstahl M, Müller CJ, Wilk E, Schughart K, Löscher W (2012) Generation and characterization of pilocarpine-sensitive C57BL/6 mice as a model of temporal lobe epilepsy. Behav Brain Res 230:182-191. CrossRef Medline

Bar-Klein G, Cacheaux LP, Kamintsky L, Prager O, Weissberg I, Schoknecht K, Cheng P, Kim SY, Wood L, Heinemann U, Kaufer D, Friedman A (2014) Losartan prevents acquired epilepsy via TGF- $\beta$ signaling suppression. Ann Neurol 75:864-875. CrossRef Medline

Bastlund JF, Jennum P, Mohapel P, Penschuck S, Watson WP (2005) Spontaneous epileptic rats show changes in sleep architecture and hypothalamic pathology. Epilepsia 46:934-938. CrossRef Medline

Becker AJ, Pitsch J, Sochivko D, Opitz T, Staniek M, Chen CC, Campbell KP, Schoch S, Yaari Y, Beck H (2008) Transcriptional upregulation of $\mathrm{Ca}_{\mathrm{v}} 3.2$ mediates epileptogenesis in the pilocarpine model of epilepsy. J Neurosci 28:13341-13353. CrossRef Medline

Borges K, Gearing M, McDermott DL, Smith AB, Almonte AG, Wainer BH, Dingledine R (2003) Neuronal and glial pathological changes during epileptogenesis in the mouse pilocarpine model. Exp Neurol 182:21-34. CrossRef Medline

Bragin A, Jando G, Nadasdy Z, van Landeghem M, Buzsaki G (1995) Dentate EEG spikes and associated interneuronal population bursts in the hippocampal hilar region of the rat. J Physiol 73:1691-1705.

Butler JL, Mendonça PR, Robinson HP, Paulsen O (2016) Intrinsic cornu ammonis area 1 theta-nested gamma oscillations induced by optogenetic theta frequency stimulation. J Neurosci 36:4155-4169. CrossRef Medline

Buzsáki G, Lai-Wo SL, Vanderwolf CH (1983) Cellular bases of hippocampal EEG in the behaving rat. Brain Res Rev 6:139-171. CrossRef Medline Cacheaux LP, Ivens S, David Y, Lakhter AJ, Bar-Klein G, Shapira M, Heinemann U, Friedman A, Kaufer D (2009) Transcriptome profiling reveals 
TGF- $\beta$ signaling involvement in epileptogenesis. J Neurosci 29:89278935. CrossRef Medline

Cant BR (1976) EEG prediction of post-traumatic epilepsy. N Z Med J 83: 416. Medline

Chauvière L, Rafrafi N, Thinus-Blanc C, Bartolomei F, Esclapez M, Bernard C (2009) Early deficits in spatial memory and theta rhythm in experimental temporal lobe epilepsy. J Neurosci 29:5402-5410. CrossRef Medline

Choi SJ, Joo EY, Hong SB (2016) Sleep-wake pattern, chronotype and seizures in patients with epilepsy. Epilepsy Res 120:19-24. CrossRef Medline

Demenet W, Kleitman N (1957) Cyclic variations in EEG during sleep and their relation to eye movements, body motility, and dreaming. Electroencephalogr Clin Neurophysiol 9:673-690. CrossRef Medline

De Simoni MG, Perego C, Ravizza T, Moneta D, Conti M, Marchesi F, De Luigi A, Garattini S, Vezzani A (2000) Inflammatory cytokines and related genes are induced in the rat hippocampus by limbic status epilepticus. Eur J Neurosci 12:2623-2633. CrossRef Medline

El-Hassar L, Milh M, Wendling F, Ferrand N, Esclapez M, Bernard C (2007) Cell domain-dependent changes in the glutamatergic and GABAergic drives during epileptogenesis in the rat CA1 region. J Physiol 578:193211. CrossRef Medline

Engel J Jr, da Silva FL (2012) High-frequency oscillations. Where we are and where we need to go. Prog Neurobiol 98:316-318. CrossRef Medline

Friedman A, Bar-Klein G, Serlin Y, Parmet Y, Heinemann U, Kaufer D (2014) Should losartan be administered following brain injury? Expert Rev Neurother 14:1365-1375. CrossRef Medline

Goldenholz DM, Seyal M, Bateman LM, Gotman J, Andrade-Valenca L, Zelmann R, Dubeau F (2012) Interictal scalp fast oscillations as a marker of the seizure onset zone. Neurology 78:224-225. CrossRef Medline

Gotman J (1991) Relationships between interictal spiking and seizures: human and experimental evidence. Can J Neurol Sci 18 [4 Suppl]:573-576. Medline

Helmstaedter C, Kurthen M, Lux S, Reuber M, Elger CE (2003) Chronic epilepsy and cognition: a longitudinal study in temporal lobe epilepsy. Ann Neurol 54:425-432. CrossRef Medline

Herrmann CS, Demiralp T (2005) Human EEG gamma oscillations in neuropsychiatric disorders. Clin Neurophysiol 116:2719-2733. CrossRef Medline

Inoue T, Kobayashi K, Oka M, Yoshinaga H, Ohtsuka Y (2008) Spectral characteristics of EEG gamma rhythms associated with epileptic spasms. Brain Dev 30:321-328. CrossRef Medline

Jukic MM, Carrillo-Roa T, Bar M, Becker G, Jovanovic VM, Zega K, Binder EB, Brodski C (2015) Abnormal development of monoaminergic neurons is implicated in mood fluctuations and bipolar disorder. Neuropsychopharmacology 40:839-848. CrossRef Medline

Kahana MJ, Sekuler R, Caplan JB, Kirschen M, Madsen JR (1999) Human theta oscillations exhibit task dependence during virtual maze navigation. Nature 399:781-784. CrossRef Medline

Kelly KM, Kharlamov A, Hentosz TM, Kharlamova EA, Williamson JM, Bertram EH 3rd, Kapur J, Armstrong DM (2001) Photothrombotic brain infarction results in seizure activity in aging Fischer 344 and Sprague Dawley rats. Epilepsy Res 47:189-203. CrossRef Medline

Ketzef M, Kahn J, Weissberg I, Becker AJ, Friedman A, Gitler D (2011) Compensatory network alterations upon onset of epilepsy in synapsin triple knock-out mice. Neuroscience 189:108-122. CrossRef Medline

Kobayashi K, Oka M, Akiyama T, Inoue T, Abiru K, Ogino T, Yoshinaga H, Ohtsuka Y, Oka E (2004) Very fast rhythmic activity on scalp EEG associated with epileptic spasms. Epilepsia 45:488-496. CrossRef Medline

Kobayashi K, Watanabe Y, Inoue T, Oka M, Yoshinaga H, Ohtsuka Y (2010) Scalp-recorded high-frequency oscillations in childhood sleep-induced electrical status epilepticus. Epilepsia 51:2190-2194. CrossRef Medline

Köhling R, Vreugdenhil M, Bracci E, Jefferys JG (2000) Ictal epileptiform activity is facilitated by hippocampal $\mathrm{GABA}_{\mathrm{A}}$ receptor-mediated oscillations. J Neurosci 20:6820-6829. Medline

Lapilover EG, Lippmann K, Salar S, Maslarova A, Dreier JP, Heinemann U, Friedman A (2012) Peri-infarct blood-brain barrier dysfunction facilitates induction of spreading depolarization associated with epileptiform discharges. Neurobiol Dis 48:495-506. CrossRef Medline

Levy N, Milikovsky DZ, Baranauskas G, Vinogradov E, David Y, Ketzef M, Abutbul S, Weissberg I, Kamintsky L, Fleidervish I, Friedman A, Monsonego A (2015) Differential TGF- $\beta$ signaling in glial subsets underlies IL-6-mediated epileptogenesis in mice. J Immunol 195:1713-1722. CrossRef Medline
Lippmann K, Kamintsky L, Kim SY, Lublinsky S, Prager O, Nichtweiss JF, Salar S, Kaufer D, Heinemann U, Friedman A (2016) Epileptiform activity and spreading depolarization in the blood-brain hippocampus are associated with impaired GABAergic inhibition and synaptic plasticity. J Cereb Blood Flow Metab. Advance online publication. Retrieved March 23, 2017. doi:10.1177/0271678X16652631. CrossRef Medline

Maheshwari A, Marks RL, Yu KM, Noebels JL (2016) Shift in interictal relative gamma power as a novel biomarker for drug response in two mouse models of absence epilepsy. Epilepsia 57:79-88. CrossRef Medline

Marcelin B, Chauvière L, Becker A, Migliore M, Esclapez M, Bernard C (2009) $\mathrm{H}$ channel-dependent deficit of theta oscillation resonance and phase shift in temporal lobe epilepsy. Neurobiol Dis 33:436-447. CrossRef Medline

McLin JP, Steward O (2006) Comparison of seizure phenotype and neurodegeneration induced by systemic kainic acid in inbred, outbred, and hybrid mouse strains. Eur J Neurosci 24:2191-2202. CrossRef Medline

Medvedev AV (2002) Epileptiform spikes desynchronize and diminish fast (gamma) activity of the brain: an "anti-binding" mechanism? Brain Res Bull 58:115-128. CrossRef Medline

Medvedev A, Mackenzie L, Hiscock JJ, Willoughby JO (2000) Kainic acid induces distinct types of epileptiform discharge with differential involvement of hippocampus and neocortex. Brain Res Bull 52:89-98. CrossRef Medline

Montagne A, Barnes SR, Sweeney MD, Halliday MR, Sagare AP, Zhao Z, Toga AW, Jacobs RE, Liu CY, Amezcua L, Harrington MG, Chui HC, Law M, Zlokovic BV (2015) Blood-brain barrier breakdown in the aging human report blood-brain barrier breakdown in the aging human hippocampus. Neuron 85:296-302. CrossRef Medline

Noè F, Pool AH, Nissinen J, Gobbi M, Bland R, Rizzi M, Balducci C, Ferraguti F, Sperk G, During MJ, Pitkänen A, Vezzani A (2008) Neuropeptide Y gene therapy decreases chronic spontaneous seizures in a rat model of temporal lobe epilepsy. Brain 131:1506-1515. CrossRef Medline

Noe FM, Polascheck N, Frigerio F, Bankstahl M, Ravizza T, Marchini S, Beltrame L, Banderó CR, Löscher W, Vezzani A (2013) Pharmacological blockade of IL-1 $\beta /$ IL-1 receptor type 1 axis during epileptogenesis provides neuroprotection in two rat models of temporal lobe epilepsy. Neurobiol Dis 59:183-193. CrossRef Medline

O'Keefe J, Recce ML (1993) Phase relationship between hippocampal place units and the EEG theta rhythm. Hippocampus 3:317-330. CrossRef Medline

Pascente R, Frigerio F, Rizzi M, Porcu L, Boido M, Davids J, Zaben M, Tolomeo D, Filibian M, Gray WP, Vezzani A, Ravizza T (2016) Neurobiology of Disease Cognitive de fi cits and brain myo-Inositol are early biomarkers of epileptogenesis in a rat model of epilepsy. Neurobiol Dis 93:146-155. CrossRef Medline

Pitkänen A, Immonen R (2014) Epilepsy related to traumatic brain injury. Neurotherapeutics 11:286-296. CrossRef Medline

Pitkänen A, Löscher W, Vezzani A, Becker AJ, Simonato M, Lukasiuk K, Gröhn O, Bankstahl JP, Friedman A, Aronica E, Gorter JA, Ravizza T, Sisodiya SM, Kokaia M, Beck H (2016) Advances in the development of biomarkers for epilepsy. Lancet Neurol 15:843-856. CrossRef Medline

Powell MJ (1977) Restart procedures for the conjugate gradient method. Math Program 12:241-254. CrossRef

Pung T, Schmitz B (2006) Circadian rhythm and personality profile in juvenile myoclonic epilepsy. Epilepsia 47 [Suppl 2]:111-114. CrossRef

Quigg M, Gharai S, Ruland J, Schroeder C, Hodges M, Ingersoll KS, Thorndike FP, Yan G, Ritterband LM (2016) Insomnia in epilepsy is associated with continuing seizures and worse quality of life. Epilepsy Res 122:91-96. CrossRef Medline

Rechtschaffen A, Kales A (1968) A manual of standardized terminology, techniques and scoring system for sleep stages of human subjects. Washington DC: US Government Printing Office, US Public Health Service.

Rizzi M, Weissberg I, Milikovsky DZ, Friedman A (2016) Following a potential epileptogenic insult, prolonged high rates of nonlinear dynamical regimes of intermittency type is the hallmark of epileptogenesis. Sci Rep 6:31129. CrossRef Medline

Roseman E, Woodhall B (1946) The electro-encephalogram in war wounds of the brain; with particular reference to post-traumatic epilepsy. Res Publ Assoc Res Nerv Ment Dis 25:200-219.

Rumelhat D, Hinton G, Williams R (1986) Learning representations by back-propagating errors. Nature 323:533-536. CrossRef

Schauwecker PE (2012) Strain differences in seizure-induced cell death fol- 
lowing pilocarpine-induced status epilepticus. Neurobiol Dis 45:297304. CrossRef Medline

Seiffert E, Dreier JP, Ivens S, Bechmann I, Tomkins O, Heinemann U, Friedman A, Gabriel S, Jauch R, Schulze K, Kivi A, Eilers A, Kovacs R, Lehmann TN, Kaufer D, Friedman A (2004) Lasting blood-brain barrier disruption induces epileptic focus in the rat somatosensory cortex. J Neurosci 24:7829-7836. CrossRef Medline

Swanson LW (2004) Brain maps III: structure of the rat brain, Ed 1. Amsterdam: Elsevier Academic.

Strijkstra AM, Beersma DG, Drayer B, Halbesma N, Daan S (2003) Subjective sleepiness correlates negatively with global alpha $(8-12 \mathrm{~Hz})$ and positively with central frontal theta $(4-8 \mathrm{~Hz})$ frequencies in the human resting awake electroencephalogram. Neurosci Lett 340:17-20. CrossRef Medline

Tarasiuk A, Levi A, Berdugo-Boura N, Yahalom A, Segev Y (2014) Role of orexin in respiratory and sleep homeostasis during upper airway obstruction in rats. Sleep 37:987-998. CrossRef Medline

Traub RD, Pais I, Bibbig A, Lebeau FE, Buhl EH, Garner H, Monyer H, Whittington MA (2005) Transient depression of excitatory synapses on interneurons contributes to epileptiform bursts during gamma oscillations in the mouse hippocampal slice. J Neurophysiol 94:1225-1235. CrossRef Medline

van Vliet EA, Forte G, Holtman L, den Burger JC, Sinjewel A, de Vries HE De, Aronica E, Gorter JA (2012) Inhibition of mammalian target of rapamycin reduces epileptogenesis and blood-brain barrier leakage but not microglia activation. Epilepsia 53:1254-1263. CrossRef Medline

Vyazovskiy VV, Tobler I (2005) Theta activity in the waking EEG is a marker of sleep propensity in the rat. Brain Res 1050:64-71. CrossRef Medline

Watson BD, Dietrich WD, Busto R, Wachtel MS, Ginsberg MD (1985) Induction of reproducible brain infarction by photochemically initiated thrombosis. Ann Neurol 17:497-504. CrossRef Medline

Weissberg I, Reichert A, Heinemann U, Friedman A (2011) Blood-brain barrier dysfunction in epileptogenesis of the temporal lobe. Epilepsy Res Treat 2011:143908. CrossRef Medline

Weissberg I, Wood L, Kamintsky L, Vazquez O, Milikovsky DZ, Alexander A, Oppenheim H, Ardizzone C, Becker A, Frigerio F, Vezzani A, Buckwalter
MS, Huguenard JR, Friedman A, Kaufer D (2015) Albumin induces excitatory synaptogenesis through astrocytic TGF- $\beta$ /ALK5 signaling in a model of acquired epilepsy following blood-brain barrier dysfunction. Neurobiol Dis 78:115-125. CrossRef Medline

White A, Williams PA, Hellier JL, Clark S, Dudek FE, Staley KJ (2010) EEG spike activity precedes epilepsy after kainate-induced status epilepticus. Epilepsia 51:371-383. CrossRef Medline

Whitney WA (1971) A direct method of nonparametric measurement selection. IEEE Trans Comput 6:1100-1103.

Willoughby JO, Fitzgibbon SP, Pope KJ, Mackenzie L, Medvedev AV, Clark CR, Davey MP, Wilcox RA (2003) Persistent abnormality detected in the non-ictal electroencephalogram in primary generalised epilepsy. J Neurol Neurosurg Psychiatry 74:51-55. CrossRef Medline

Winson J (1974) Patterns of hippocampal theta rhythm in the freely moving rat. Electroencephalography Clin Neurophysiol 36:291-301.

Winson J (1978) Loss of hippocampal theta rhythm results in spatial memory deficit in the rat. Science 201:160-163. CrossRef Medline

Wu JY, Koh S, Sankar R, Mathern GW (2008) Paroxysmal fast activity: an interictal scalp EEG marker of epileptogenesis in children. Epilepsy Res 82:99-106. CrossRef Medline

Yaari Y, Yue C, Su H (2007) Recruitment of apical dendritic T-type Ca2+ channels by backpropagating spikes underlies de novo intrinsic bursting in hippocampal epileptogenesis. J Physiol 580:435-450. CrossRef Medline

Yamazaki M, Chan D, Tovar-Spinoza Z, Go C, Imai K, Ochi A, Chu B, Rutka JT, Drake J, Widjaja E, Matsuura M, Snead OC 3rd, Otsubo H (2009) Interictal epileptogenic fast oscillations on neonatal and infantile EEGs in hemimegalencephaly. Epilepsy Res 83:198-206. CrossRef Medline

Yang J, Houk B, Shah J, Hauser KF, Luo Y, Smith G, Schauwecker E, Barnes GN (2005) Genetic background regulates semaphorin gene expression and epileptogenesis in mouse brain after kainic acid status epilepticus. Neuroscience 131:853-869. CrossRef Medline

Zeng LH, Rensing NR, Wong M (2009) The mammalian target of rapamycin signaling pathway mediates epileptogenesis in a model of temporal lobe epilepsy. J Neurosci 29:6964-6972. CrossRef Medline 